\title{
Los emprendimientos familiares: una aproximación desde la antropología
}

\author{
Family Start-Ups: an Anthropological Perspective
}

\author{
Norling Sabel Solís Narváez \\ Docente-Investigador \\ Universidad Nacional Autónoma de Nicaragua, UNAN-Managua \\ naviargentinarodriguezrivera@gmail.com \\ ID Orcid: https://orcid.org/0000-0003-1928-1108 \\ Correo: nsolis@unan.edu.ni
}

\section{Resumen}

El ensayo intenta cuestionar los principios elementales del desarrollo local, que se enmarcan sobre todo entre los emprendimientos familiares que generan circulación de bienes, pero además de relaciones familiares, e inter vecinales. Esta propuesta de construcción parte de un origen ancestral de las economías familiares, principalmente de las comunidades rurales, donde aún se percibe un fuerte arraigo a patrones culturales de comportamiento de reciprocidad.

El propósito de este ensayo es fundamentar que la cultura del emprendimiento es una actividad intrínseca a la cultura propia nicaragüense que data desde los primeros pobladores. Y que además se debe considerar como una estrategia de desarrollo local, que resiste las rupturas del sistema capitalista, y que influye en la economía global, que afecta directa e indirectamente las economías locales.

El trabajo, que se fundamenta con textos de referencias y comparaciones argumentativas, expone como el emprendimiento no es una invención categórica nueva. Sino que se entiende en la actualidad como elemento mercantil, obviando el valor de uso comunitario como elemento esencial de la cultura local.

Palabras claves: Emprendimiento, cultura local, economía local, herencia ancestral

\section{Abstract}

This essay attempts to question the basics principles od local development, which are framed, above all, between family entrepreneurships that generates the circulation on goods, as well as family and inter-neighborhood relations. The creation of this proposal originates from ancestral knowledge on family economies, mainly on rural communities, where a strong attachment to cultural patterns of reciprocal behaviors is still perceived. The purposes of this essay us to establish that the culture of entrepreneurship is an intrinsic activity to the Nicaraguan culture that dates to the first settlers. It should also be considered as a local strategy for development that resists the ruptures of the capitalist system, and its influence in the global economy, that affects directly and indirectly the local economies. This project is based on texts of references and argumentative comparisons, exposing that entrepreneurship is not a new invention. It is currently understood as a commercial element, obviating the value of the community use as an essential element of the local culture.

Keywords:Entrepreneurship, local culture, local economy, ancestral heritage 


\section{Introducción}

Nicaragua es una fábrica de personas emprendedoras. Actualmente se ha concebido que el emprendedurismo es un proceso creado bajo la economía global, que ha configurado sus estrategias para mantener bajo control a más personas y no sólo por consumo, sino por mano de obra.

Pero la economía local en Nicaragua siempre ha estado respaldada y fomentada por una cultura de emprendimiento. La misma cultura, que no es nueva, ni reciente, ni se inventó hace unos años por la corriente capitalista.

Ciertamente en las economías locales, de las comunidades rurales y espacio urbanos, ha existido una fuente de sobrevivencia basada en pequeños negocios familiares, que nacen como emprendimientos. Prueba de eso, es que en Nicaragua aunque sigue siendo altamente agrícola, en las comunidades la gente tiene economías alternativas crecientes.

En los actuales informes del Ministerio de Economía Familiar Comunitaria, Cooperativa y Asociativa (MEFC$\mathrm{CA}$ ), existen evaluaciones positivas de incremento en negocios familiares. Más allá de los datos cuantitativos que indican las proyecciones del Ministerio en el que existen al menos 2500 negocios sólo en Managua, también establecen mecanismos de relación entre la comunidad y los negocios.

Se reflexiona desde este ensayo que los emprendimientos son una práctica sustan- "la cultura funciona como un regulador de los materiales o productos que se emplean para satisfacer una necesidad." ha estado ligado al trabajo, por consiguiente diría Engel (1876) su desarrollo socio-cognitivo está ligado al mismo.

Las actividades dedicadas a satisfacer las necesidades básicas tal cual menciona Maslow (1954), están dirigidas por la misma creatividad de las personas. Basado en eso, es importante considerar que la cultura donde se desarrollan los individuos influye directamente en el proceso y nivel de creatividad. Para comprender esta lógica de uso y funcionalidad de la creatividad es importante descifrar la cultura, la misma que se entiende como

"el conjunto de comportamientos y creaciones humanas socializadas y estandarizadas producto de la actividad social de los seres humanos. Consiste en ideas y sentimientos, formas de actuar o de comportarse y también objetos sociales, constituyendo un sistema coherente e interrelacionado de estructuras mentales, sociales y materiales." (Berdichewsky, 2002)

Berdichewsky (2002) se refiere a que los procesos que emplean los grupos humanos en cada cultura, contiene un arraigo estructural en los cimientos mentales, sociales y materiales. Por ende, lo que el individuo desarrolla para satisfacer una necesidad básica está ligada a la forma y manera de entender el mundo, es decir, primero como se estructura en las mentes individuales, para luego colectivizarla en lo social y así mismo materializarla.

Bajo esta lógica, la cultura funciona como un regulador de los materiales o productos que se emplean para satisfacer una necesidad. Los grupos sociales, culturalcial en las comunidades, que no son de tendencias nuevas. Además que la misma cultura genera a través de esta práctica una estrecha relación entre los que participan, ya sea entre los miembros directos o bien entre la comunidad. Se entiende que los emprendimientos locales son sustanciales para el mantenimiento de las economías familiares.

\section{Iniciativas económicas como práctica de la cultura local}

El ser humano dentro del andamiaje sociocultural ha implementado distintos mecanismos para crear y difundir iniciativas locales de desarrollo. Históricamente mente dan respuesta a los vacíos y necesidades, empleando contradicciones internas, haciendo uso en la praxis de la "prueba-error", manifestado directamente en el devenir histórico de cada grupo como se expresa en los materiales como vestigios de esta cultura (Althusser, 1967).

Por esa razón, es importante considerar en el análisis de los emprendimientos la categoría económica y la cultura, como dos elementos sustanciales en el proceso de creación de productos para satisfacer necesidades. Considerando esto, un aspecto que es necesario comprender, que la cul- 
tura del emprendimiento, no es algo nuevo, ni reciente, ha sido por mucho tiempo un proceso de desarrollo gestionado por las necesidades sustanciales que atraviesan los grupos humanos y que los mismos resuelven con creatividad directamente vinculada con su cultura.

Es importante considerar dos aspectos en el emprendimiento actual, primero; que tiene una lógica histórica, es decir, es evidencia de una cultura propiamente enajenada o negada (Batalla, 1990), donde el emprendimiento y sus actividades económicas no han sido valoradas y mucho menos calificadas en el sector productivo. Dentro de este panorama se encuentran remanencias de culturas originales, pueblos originarios o bien rasgos precolombinos, en las actuales expresiones donde se refleja a un campesino, o indígena ingeniando actividades económicas de aprovechamiento de sus recursos y que sencillamente son la clase desprestigiada del sector económico.

Y segundo que las coyunturas socioeconómicas globales actualmente influyen en las comunidades, pero que las mismas resuelven desde la cultura y comprensión de la realidad. Bajo esta lógica es necesario decir, que aunque existen rupturas o transformaciones económicas (Polanyi, 2007) que re-direccionan las estrategias de desarrollo nacional, y por tanto las locales, donde el agente principal transformador y por ende transformado son los actores locales. Sin embargo, aun cuando existen este tipo de tendencias, la transformación únicamente es acompañada por un proceso histórico en las comunidades: los emprendimientos locales transformadores de desarrollo.

Dicho en otras palabras, los procesos de emprendimientos deben ser analizados por un devenir histórico-social-cultural, de sentido comunal y familiar. Y por un proceso de coyuntura socioeconómica global, dando pautas a comprender que cualquier emprendimiento surge como un producto necesitado y necesario, que por su naturaleza será socializado y además adjudicado como propio a la comunidad o grupo.

Por cuestiones necesariamente vinculantes anteriormente dicho, se considerará un repaso a grosso modo el devenir histórico del emprendimiento y luego la coyuntura socioeconómica que ha desarrollado hincapié en este tema. Por supuesto, esto no debe entenderse como la razón única, existen maneras de entender el emprendimiento, sin embargo, los emprendimientos familiares y juveniles en la actualidad, tienen arraigo a la cultura y por esa misma razón son sostenibles.

\section{Emprendimientos familiares con arraigo ancestral en las comunidades locales}

Desarrollando el devenir histórico, existe diferencias claras en cuanto a los procesos históricos en Nicaragua, por un lado el desarrollo del Pacifico conformados mayoritariamente por grupos mesoamericanos, íntegramente influenciado por la corriente occidental, directamente colonias españolas y norteamericanas. Los pueblos mesoamericanos provenientes del sur de México de influencia Náhuatl, traían consigo todo un bagaje cultural centrado en el maíz como producto base y en el material cultural siendo el metate como prueba histórica y evidente de una cultura de maíz (Bethell, 1990).

La Costa Caribe, que fue influenciada y algunos teóricos sostienen que hasta negociadas entre los pueblos originarios y las colonias inglesas como francesas. Centrados en una cultura de tubérculos y pesca, en un principio, que luego fue teniendo un proceso centrado en las economías de enclaves. (Webb, 2012)

Al parecer históricamente estas regiones tenían algo en común en las actividades económicas, el significado cultural a cada actividad, incluso aquellas que hoy entenderíamos como emprendimiento, nacieron con una lógica de valor de uso. Vagamente esto implicaba para estos pueblos generar un producto que satisficiera alguna necesidad pero que el mismo producto, no tendría un valor económico.

Los pueblos originarios en Nicaragua desarrollaron distintos productos como forma de emprendimientos, sin embargo no todos los bienes tenían un valor comercial, sino utilitario. Claro en el proceso de la intervención de las colonias, estos pueblos fueron pasando sus economías de un estadio comunal, a uno mercantil. Propiamente li- 
gado además a los estadios evolutivos del ser humano por lo cual, es necesario inferir que lo que resulta de la actual Nicaragua, es apenas un mosaico de las anteriores herencias culturales y estadios. (Morgan, 1881)

Sin embargo, en las crónicas de Oviedo señala claramente que en los "tiangues", ubicados en las plazas centrales de aquellos pueblos, la gente intercambiaba productos que básicamente le excedían con otro que necesitaran, esto solo se enmarcaba desde productos de consumo con valor de uso (Oviedo, 1976). Entre estos productos que se mencionan en las crónicas no hacen referencias únicamente a productos cosechados como el maíz, frijol o tubérculos, también refiere a materiales de uso, como metates, cerámicas, morteros etc.

"en la fase de la economía doméstica, cada bien es consumido en la economía que lo ha creado; en la fase de la economía urbana, ese bien pasa de inmediato de la economía que lo crea a la que lo consume; en la fase de la economía nacional, ese bien, para ser creado, al igual que después de haberlo sido, recorre economías distintas: circula." (Bucher, 1974)

Por supuesto, los pueblos originarios cuando creaban un bien, este material pasaba a tener un función, un uso específico, la comunidad lo asimilaba, pero el mismo no se comercializaba, se intercambiaba, incluso refiere en sus textos de crónicas de Oviedo que entre los señores intercambiaban como prestigio parte de los bienes materiales que producían, así el emprendimiento se colectivizaba y se volvía parte de la comunidad. Es por ello que podríamos entender, porque en el territorio nicaragüense se consideran pan regional algunas cerámicas donde las pruebas arqueológicas evidencian restos en todo el territorio como el papagayo policromo (Vasquez \& Espinoza Vallejos, 2006).

Los pueblos precolombinos de la región nicaragüense, fueron emprendedores, culturalmente tenían una corriente dedicada a crear artefactos para propiciar la satisfacción de una necesidad, por ejemplo crear hachas, vasijas, platos y hasta urnas de uso rituales como prác- ticos en la cotidianidad de la población. (Vasquez \& Espinoza Vallejos, 2006)

Esto únicamente sugiere que el emprendimiento, no es algo nuevo, si lo es basado en la lógica de consumo que se establece en la actualidad. Como infiere Bucher (1974), las sociedades van transitando estadios, esto van desde el valor de uso como ya se mencionaba, hasta el valor mercantil, pero esto además se debe entender que aunque las poblaciones focalicen nuevos emprendimientos, están estrechamente ligados a los orígenes de las familias y su cultura, por tanto responde a valores socioculturales para satisfacer necesidades económicas.

Las familias en el campo, realizan emprendimientos, con altas creatividades, esto se entiende por los miembros como iniciativas de sobrevivencia. Esto implica, que los emprendimientos de valor familiar, que utilizan recursos familiares para satisfacer una necesidad están entendidos desde la antropología económica como economías de sobrevivencia y subsistencias. Por esa razón, significan emprendimiento en tres niveles: cultural, social y económico, porque se comprende que el bien circula en la sociedad con valor social, cultural y mercantil, además la invención familiar, cuando circula en la comunidad se entiende como emprendimiento, aunque también con valor de uso, o funcionalmente cultural.

De forma, que para entender los criterios de desarrollos locales, es necesario el reconocimiento del emprendimiento desde la cultura negada de los pueblos originarios. Supone en todo caso, dar respuesta y mecanismo de proyección a las actividades que surgen en el seno de la comunidad, por ende los emprendimientos nace como necesidad inmediata que puede resultar en grandes aportes al desarrollo local.

\section{Cooperatividad y solidaridad en los emprendimientos familiares $y$ las transformaciones económicas}

Ahora bien, la segunda forma para entender los procesos económicos es comprender las coyunturas socioeconómicas globales, para esto es importante men- 
cionar que el emprendimiento también resulta como respuesta en la últimas décadas a la "crisis global" en la que surgen nuevos índices de desempleo como lo indica Inmanuel Wallerstein (1974) sobre las decadencias del sistema mundo, el capitalismo como tal, que ha creado un fuerte déficit de miles de jóvenes por año que se encuentran en el desempleo.

Ante esta situación, en nuestra región latinoamericana y caribeña, sobre todo en las últimas dos décadas, han surgido distintos programas de estados y políticas de gobierno principalmente progresistas de izquierda, que han dado prioridad a la creatividad juvenil.

Ciertamente el emprendimiento, siempre ha existido, evidenciado como ya lo decíamos desde los pueblos originarios pero además desde las raíces familiares. Por ejemplo, en décadas de los '50 en

Los emprendimientos son percibidos con poca relevancia en las comunidades, aunque son sin duda la fuente de desarrollo local, sobre todo bajo la cobija de cooperativismo y solidari- co no es solo nacional, sino también internacional, y esto ha sido constante en el que el capitalismo está centrado en obtener (dominar) los medios de producción, que además intenta dominar el recurso humano y mantenerlo bajo su control. Por supuesto entre sus estructuras posee momentos de transformaciones y en lo que se evidencia una nueva ruptura, debilitando los sistemas económicos subalternos, provocando en algunos casos choques sociales y déficit en empleo, desestabilizando las sociedades.
Nicaragua, la clase pudiente era mínima, la mayoría de la población se dedicaba a generar sus propios ingresos empleando estrategias económicas alternativas.

Los emprendimientos son percibidos con poca relevancia en las comunidades, aunque son sin duda la fuente de desarrollo local, sobre todo bajo la cobija de cooperativismo y solidaridad. Ambos elementos mencionados, no son ni siquiera nuevos, puesto que los pueblos originarios y las comunidades con remanencias culturales originales, han enmarcados lazos de solidaridad y cooperatividad que ha funcionado fielmente.

Sin embargo no es reciente, (aunque en Nicaragua en la actualidad se maneja mucho mejor el cooperativismo), que se niega o rechaza la importancia de estos elementos, por lo menos así se negaba en años anteriores a lo que Polanyi (2007) denominaría "la crisis de la economía liberal", en la actualidad el reconocimiento de esas características propias de los pueblos de descendencia mesoamericanas, afrodescendientes, y caribeñas han posibilitado proyectos de Estados como el Buen Vivir en Ecuador, y los avances en Nicaragua sobre el Proyecto de Gobierno solidario y cooperativo, además de mencionar el Programa Aprender, Emprender y Prosperar, como bálsamos de esta nueva propuesta de arraigo cultural.

Hay que agregar además que el panorama económi-
Lo anterior genera la reconstrucción de las raíces culturales del emprendimiento, dando respuesta a las necesidades desde la creatividad juvenil, familiares o cualquier agrupación, como respuesta o resistencia al capitalismo aportando a las economías familiares pero además nacionales.

Tomando la perspectiva substantivista y formalista de la antropología económica, como un fundamente teórico que permite analizar cómo las personas siendo parte de un grupo particular van a buscar medios para obtener algunas ganancias del bien que traten de vender. Así la necesidad genera en las personas creatividad, y estos elementos permiten una categoría de emprendimiento.

"El significado substantivo de económico deriva de la dependencia del hombre, para su subsistencia, de la naturaleza y de sus semejantes. Se refiere al intercambio con el medio ambiente natural y social, en la medida en que este intercambio tiene corno resultado proporcionarle medios para su necesaria satisfacción material." (Godelier, 1974, pág. 155)

La necesidad de vender algo "medio transformado o adaptado" para obtener una ganancia le permite la persona hacer uso de la naturaleza, transformarla en un producto y vincular está a una necesidad, luego se adquiere y/ o transforma en el bien emprendido, que pasaría a formar parte de un círculo comercial ahora en esta tendencia actual, funciona el cooperativismo cuando el bien lo producen varias personas, o bien establecen relaciones solidarias de comercios. 
Ciertamente "La transformación implica un cambio en la motivación de la acción de parte de los miembros de la sociedad: la motivación de la subsistencia debe ser sustituida por la motivación de la ganancia.” (Polanyi, 1944, pág. 90)

Pero ejemplo sencillos de emprendimientos son los comerciantes ambulantes que venden tajadas de mango en bolsa cerca de las paradas de buses, utilizan el medio natural (mango), lo transforman en un producto (ya en tajadas) y se lo venden a las personas que sienten una satisfacción por comer mangos.

Esto no ocurre así de forma simple, existe un análisis de mercadeo claramente empírico, aunque no parezca por parte de quienes identifican la necesidad y además asumen directamente el emprendimiento para identificar que el producto que elabore será vendido en ese lugar por el tipo de persona que frecuenta dicho sector o pertenece a la localidad.

Pero en todo este aparato colectivo del emprendimiento y para responder al mismo surge toda una estructura funcional de parentesco en la que todos los involucrados cumplen con eventos o momentos necesarios en el proceso del emprendimiento. Por tanto argumenta un trabajo de todos los miembros de la familia por satisfacer una necesidad, la misma era sustentada por cada miembro de la familia, que tendría una asignación particular dentro del grupo. Como propone Malinowski (1922), la función social de cada miembro le orientaba a generar estrategias de acción para satisfacer las necesidades colectivas en las Islas Trobiand.

Lo cual deben lograr satisfacer a partir de "la atribución o distribución, lejos de seguir un esquema tan simple, aparece de nuevo lleno de intrincaciones y ofrece muchos rasgos de interés económico. De éstos, los dos más importantes son: las obligaciones impuestas por el parentesco, y las deudas y tributos." (Godelier, 1974, pág. 93)

Lo antes dicho argumenta la tendencia de los emprendimientos como un enfoque anti capitalista, bajo una lógica de bienestar común familiar, que en principio nace para la satisfacción de las necesidades, pero que se empodera y se mantiene a la vez como una respuesta ante los embate económicos del capitalismo, por tanto el emprendimiento genera una satisfacción económica, social, cultural y estructural.

Esta tendencia de una necesidad colectiva, inclina al emprendimiento individual con razón y efecto para el mismo grupo familiar, es decir, aunque los emprendimientos surgen de una idea individual, la misma tendrá una acción y cooperación colectiva, además los emprendimientos para tener un sustento y sostenibilidad anti capitalista deben tener razón y apego a la cultura local, desarrollando economías locales bajo las rupturas económicas globales.

\section{Conclusión}

Las economías locales están enmarcadas directamente con emprendimientos familiares, estrechamente vinculadas a las culturas ancestrales y devenir históricos de las mismas. Con esto implica que la cultura del emprendimiento, no es fruto de un proceso reciente, sino que se evidencia desde las vasijas que elaboraron los primeros pobladores.

Además se puede inferir a manera de conclusión en este ensayo, que las culturas autóctonas, tenían un dominio del medio ambiente, lo que posibilitaba el desarrollo de estrategias económicas. En la actualidad, las personas y familias que se dedican a crear espacio de negocios o bien emprendimientos como procesos de liderazgos en las economías locales están ligadas a su medio y la comprensión cultural del mismo.

Por tanto, una persona que vive en la costa de playas tendrá un emprendimiento diferente, de quien vive en llanos. En realidad la concepción de emprendimiento será el mismo, sin embargo están encaminados por la cultura de las personas y las formas de ver y entender el mundo.

Por supuesto, se concluye que las formas de emprendimientos en los pueblos ancestrales tendría un valor de uso, más que comercial, por lo tanto los artefactos que creaban, eran de uso domésticos. Sin embargo en la actualidad los productos que se generan aunque pueden tener un valor de uso, también pueden circular como bien de consumo para quien no tiene el producto pero le sería útil.

Los emprendimientos actualmente son considerados como mecanismos de resistencia ante la crisis económica de la ciudad, es decir, a medida que la economía se torna más compleja, las familias de sectores rurales y periféricos tienden a tener ingeniosas ideas para "salir adelante", considerando su medio y la necesidad de sobrevivencia, se crean medios para satisfacer necesidades inmediatas. 
Para algunos casos de emprendimientos, el valor de uso pasa de función familiar a consumo, es decir, que las familias pueden crearse una pequeña fábrica de vinagre de maduro, algo que hacían para la familia, se convirtió en su emprendimiento, pasó de uso funcional a ocupar un uso mercantil de consumo.

Finalmente los proyectos que impulsan programas de emprendimientos en las comunidades locales deben además estar estratégicamente vinculadas con procesos de interculturalidad permanente. Fomentando la construcción de aprendizaje, sobre la base del conocimiento empírico, la cultura local y las proyecciones locales de desarrollo, de forma que los programas sustenten dichas iniciativas.

\section{Bibliografía}

Althusser, L. (1967). Materialismo Dialéctico y Materialismo Histórico. Pensamiento crítico, Habana, Cuba.

Batalla, G. B. (1990). México profundo: una civilización negada. México : Grijalbo.

Berdichewsky, B. (2002). Antropología Social: Introducción, Una visión global de la humanidad . Buenos Aires, Argentina: Ediciones Libros ARCES-LOM .

Bethell, L. (1990). Historia de América Latina . Barcelona: Editorial Crítica.

Bucher, K. (1974). Estadíos de la evolución economica (1893). En M. Godelier, Antropología y economía (págs. 84-85). Barcelona: Editorial Anagrama.

Engels, F. (1876). El papel del trabajo en la transformación del mono a hombre. Berlin .
Godelier, M. (1974). Antropología y economía . Barcelona: Analgrama.

Malinowski, B. (1922). Los argonautas del Pacífico Occidental . Barcelona: Ediciones Peninsula .

Maslow, A. (1954). Motivación y persoalidad . California: Harper .

Morgan, H. L. (1881). La sociedad Primitiva . s.e.

Oviedo, G. F. (1976). Nicaragua en las Crónicas de Indias: Oviedo, Introducción y notas de Eduardo Pérez Valle .Managua : Fondo de Promoción Cultural-Banco de América.

Polanyi, K. (1944). La Gran Transformación. Los origenes politicos y económicos de nuestros tiempos. México: Fondo de Cultura Económica.

Polanyi, K. (2007). La Gran Transformación. Crítica del liberalismo económico. Madrid: Quipu editorial.

Vasquez, R. G., \& Espinoza Vallejos, S. (2006). Una nueva teoría acerca de los emplazamientos (Chorotega Nicarao) en la Nicaragua precolombina. Revista del Museo Chorotega Nicarao- Enrique Berio Mantica D., 54-61.

Wallerstein, I. (1974). El moderno sistema mundial: la agricultura y los origenes de la economia mundo europea en el siglo XVI. España : Siglo XXI.

Webb, Y. H. (2012). Una Historia Diferente. Apuntes básicos sobre la historiografía de los pueblosindígenas y las comunidades étnicas de las regiones autónomas de la costa caribe nicaragüense. HURACCAN.

\section{Norling Sabel Solís Narváez}

Licenciado en Antropología Social, está cursando la maestría en Antropología y Liderazgo Social (Tercera Cohorte). Actualmente labora como docente-investigador del Departamento de Antropología de la UNAN-Managua. Comunicador cultural y experto en los temas de cultura e identidad en mercados populares. Premiado con el reconocimiento a la Excelencia Investigativa por el Primer Lugar obtenido en la Jornada Universitaria de Desarrollo Científico, JUDC 2013. Ha desarrollado estudios paralelos sobre investigación, innovación y emprendimiento brindado por INIES en 2013. Ha participado como ponente en diferentes congresos nacionales y encuentros a nivel centroamericano. En el 2015 ha coordinado el Primer Encuentro Centroamericano de Estudiantes de Antropología (ECEA). Facilitador de talleres populares a jóvenes con temáticas de liderazgo social juvenil en el Centro Cultural Batahola Norte. Ha participado como colaborador en investigaciones arqueológicas desarrolladas por el arquitecto Ramiro García en Chichigalpa-Chinandega en 2005. Ha colaborado en montaje de museos de Arte Precolombino en Chinandega. 